\title{
The Culture of Excellence of Private Higher Education Institutions
}

\author{
GENARO V. JAPOS \\ genarojapos@gmail.com \\ Liceo de Cagayan University
}

Date Submitted: September 25, 2007

Final Revision Accepted: November 28, 2007

\begin{abstract}
The study investigated the culture of excellence of six top performing private higher education institutions in Northern Mindanao. These descriptive study respondents involved 80 academic administrators and program chairpersons as respondents. The frequency, percentage, weighted mean, and analysis of variance were used. These are the conclusions of the study. The culture of excellence is largely a function of efficient and effective quality assurance management systems such as voluntary accreditation and international certification. The external evaluation in the quality assurance audits promotes the achievement of comparable standards with the best practices in the Philippines and abroad. Some accredited schools have acquired ISO certification, a move that enhances the quality assurance management system. The schools' culture of excellence generates the intended teaching and learning outcomes manifested through integral development of graduates, high performance in licensure examinations, high employability, and global competitiveness. The efficiency and effectiveness of the governance and management of the schools have an overriding influence on the quality of teaching and research, support to students, relations with the community, and management of resources. Generating higher research productivity among the faculty, fund sourcing from partnership and entrepreneurial activities that generate non-tuition revenues remain the serious challenges of the school management.
\end{abstract}

Key words - Culture of excellence, governance and management, teaching and research, quality assurance 


\section{INTRODUCTION}

The greater bulk of the responsibility to educate college-bound students falls squarely on the more than 1,000 higher education institutions, 85 percent of which are private colleges and universities. (Alcala 2000). Of this number, less than five percent have reached Level III accreditation, have been cited for excellence in licensure examinations by the Professional Regulation Commission, and have been conferred deregulated or autonomous statuses by the Commission on Higher Education (Valisno 2000).

Despite serious constraints brought about by limited resources in the operations of private schools, handfuls have achieved quality and excellence through sincere commitment and dedication to serve the students. These few schools have developed their own quality assurance programs honed for years of accreditation and compliance with CHED standards.

In Caraga Administrative Region, Fr. Saturnino Urios University has been in existence for 104 years. Founded by Fr. Saturnino Urios SJ, the school has been ranked 14th among the top 20 schools in the country in a 10-year study by the CHED and the PRC. The St. Joseph Institute of Technology has existed in Butuan in less than three decades, yet is has dominated the landscape of technological education in the region. It is ISO Certified by the Dets Norske Veritas. The St. Paul University has had tremendous growth since the transfer of ownership from the Diocese of Surigao when it was still San Nicolas College to the Daughters of St. Paul Congregation. Its college of education is a Center of Development.

In Region 10, Liceo de Cagayan University towers among her peers as Center of Excellence in Nursing Education in two regions. It has been granted deregulated status in 2003. The College of Arts and Science and Commerce are due for Level III Accreditation in December of 2005. Capitol University was granted the deregulated status in 2002. Most of its academic programs are accredited. It has its own hospital for its nursing students and has three other branches in the Philippines. Lourdes College has achieved Level III accreditation. The school has consistently excelled in the licensure examination for teachers.

Each of these excelling schools provides inspiring models for other private schools to emulate in Northern Mindanao.

The results of the study are significant to the following sectors:

The Commission on Higher Education. The findings of the study can serve as vital inputs on the monitoring of educational quality among schools with track record of excellence. The documented best practices would serve as models for other educational institutions.

The Selected Private Higher Education Institutions. The conclusions 
generated from the study will serve as affirming feedback on the impact of the implementation of their quality assurance system as basis for future enhancement of their culture of excellence.

The Communities of Northern Mindanao. The study can serve as a form of advocacy of the private HEIs to the communities of Northern Mindanao regarding the effectiveness of their educational services.

The Educational Researchers. The results of the study can generate fresh insights into the promotion of excellence in higher education. The study can provide new leads for research on quality and excellence. The study focused on the culture of excellence among private higher education institutions of Northern Mindanao. It investigates the aspects of governance and management, quality of teaching and research, support to students, relations with the community, and management of resources. The study is limited to private higher education institutions that have been certified as having demonstrated track record of excellence through conferment of deregulated or autonomous status and high performances in the national licensure examinations. The coverage of the study was the first semester of 2005. The respondents of the study were the 80 administrators and faculty chairpersons. For ethical reason, no individual school was identified in the data analysis.

\section{FRAMEWORK}

The culture of excellence has its legal mandate in Article XIV, Section 1 of the 1987 Philippine Constitution that states, “The state shall protect and promote the right of all citizens to quality education at all levels and shall take appropriate steps to make such education accessible to all". This is the declared policy of the Commission on Higher Education to support and value the significant role of higher education institutions, academic community, and other stakeholders in establishing a quality assurance system for the higher education sector. It looks at the effectiveness of an institution in its entirety, particularly, the development of institutional systems that ensure the quality and standards of programs (CHED Memo No. 15 Series of 2005).

Quality assurance is fundamental in the pursuit of quality in higher education. It has a vital role in the success of higher education institutions. It is focused on developing and managing educational programs and services, thus, enabling them to attain standards comparable to national, regional, and international higher education. Fostering, managing, and governing a quality learning environment through effective structures and mechanisms require collaboration among policy 
makers, educators, and other stakeholders. It considers continuous improvement and draws on best practices in delivering and improving educational provisions (CHED Memo 16, Series of 2005).

The Primer on Quality Assurance, Monitoring and Evaluation of HEIs (2005) stipulates that a higher education institution, which has a powerful culture of excellence, is able to maintain, develop, and continually appraise its cultural values. It provides skills and expertise to support the economic and development needs of the Philippines. It develops individuals to be self-reliant and entrepreneurial. It prepares individuals to play an active role in civil society. It provides the country with a pool of knowledge and expertise that will contribute to all aspects of social and economic development.

The framework of a culture of excellence takes into consideration five performance measures identified by the Commission on Higher Education: governance and management, quality of teaching and research, support to students, relations with the community, and management of resources.

Governance and management includes the institution's governance arrangements that demonstrate probity, strategic vision, accountability, awareness and management of risk, and effective monitoring of performance. It examines the institution's management, financial control, and quality assurance arrangements whether these are sufficient to manage existing operations and to respond to development and changes (Thompson and Strickland III 2001).

Quality of teaching and research looks into the institution's efforts to set and achieve program standards, to maintain its status as center of excellence and center of development, and to enhance research capability.

Support for students analyzes the provision of scholarship and study grants on merit to support the most able students in programs that develop competences needed to support the Filipino economy and to enable the country to compete in global labor markets. It also examines the provisions of equity and access seen in the light of recruiting, admitting, and supporting students from indigenous groups, low income classes, and other special groups such as the handicapped and foreign students. It also deals with programs for student services to support the non-academic needs of the students.

Relations with the community involves best practices in programs that take into consideration the social, cultural, economic, and developmental needs of the country at the local, regional, and national levels. It also includes networking and linkages with other institutions and organizations in the country and abroad. It embraces extension programs that are responsive to the needs of the community for people empowerment and self-reliance (Layton 1995).

Management of resources focuses on the institution's faculty profile with respect 
to the adequate number of faculty with appropriate expertise and competence to teach the courses offered by the institution. It also documents practices on the effective use of information and communication technology to support standard learning and to manage its academic affairs. It also looks at sustainable and appropriate income generating strategy to support its development plans.

\section{OBJECTIVES OF THE STUDY}

The study pursued the following objectives: (1) to describe the extent of the practice of a culture of excellence of the private higher education institutions as rated by the administrators and faculty chairpersons; (2) to determine the differences in the practice of a culture of excellence among the private higher education institutions; and (3) to trace emerging trends of practices of a culture of excellence in the private schools.

\section{METHODOLOGY}

The study used the descriptive design involving survey, interviews, and documentary analysis. It is descriptive because it sought to portray the culture of excellence among the private higher education institutions in Northern Mindanao. The study covered the top performing schools in Region 10 and Caraga Region. The respondent schools met one or more of the following criteria: (1) topperforming school in board examination as cited by the Professional Regulations Commission, (2) Center of Development or Excellence, and (3) Deregulated and/or Autonomous.

Table 1. Distribution of respondents

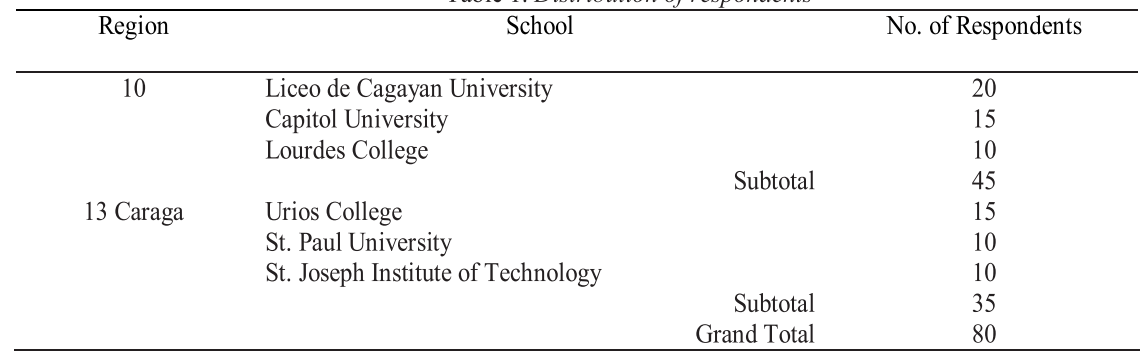

The study used the non-probability sampling design. The respondents were the academic administrators and program chairpersons who the most knowledgeable persons are concerning the implementation of quality assurance program that promotes a culture of excellence. 
The items in the research instrument were taken from the institutional quality assurance, monitoring and evaluation of CMO No. 16 Series of 2005. The researcher designed the format of the instrument by adding the rating scale and the corresponding descriptions.

Performance Measure

I. Governance and Management

II. Quality of Teaching and Research

III. Support for Students

IV. Relations with the Community

V. Management of Resources
No. of Indicators

17

32

14

14

18

Total

The researcher contacted the administrators of the respondent schools and he conveyed the idea of conducting a study on the culture of excellence of the institutions as a baseline data in the preparation of IQUAME. To give flesh to the responses, the researcher made a documentary analysis of existing evidences. Interviews were done to generate explanations on the gaps in the ratings of the items and the documents.

The frequency, percentage, weighted mean, and analysis of variance were used.

\section{RESULTS AND DISCUSSION}

Governance and Management

Governance as a criterion stipulates that the institution's governance arrangements demonstrate probity, strategic vision, accountability, quality assurance and management of risks, and effective monitoring of performance (Table 2).

Generally, the schools' governing body demonstrates integrity and objectivity in the transaction of its business, and follows a policy of openness and transparency in the dissemination of its decisions (4.19 VS). This indicator is accomplished through the use of democratic processes such as budget hearing for all offices, regular state-of-the-institution addresses of the President to inform the academic community of the progress, general assemblies to bring directly to the people the issues, regular dialogues, and publication and dissemination of decisions of the top management. Some schools have strategic plans that identify financing, physical resource and staff, and strategies necessary to achieve the objectives of the plans. All schools have development plans made by middle managers, but few schools have strategic plans crafted by the top management. 
1. The governing body demonstrates integrity and objectivity in the transaction of its business, and follows a policy of openness and transparency in the dissemination of its decisions.

2. The governing body considers and approves the strategic plan of the institution, and identifies the financial, physical resource and staffing strategies necessary to achieve the objectives of the plan.

3. The governing body monitors regularly the performance of the institution against its planned strategies and operational targets.

4. The governing body ensures the solvency of the institution, and safeguards its assets.

5. The governing body approves the financial strategy, annual operating plans and budgets of the institution; and ensures the existence and integrity of financial control systems.

6. The governing body ensures that funds provided by CHED, other Government bodies, or nonGovernmental organizations, are used in accordance with the terms and conditions specified when those funds were made available.

Mean VD

7. The governing body directs and oversees the institution's arrangements for internal and external audit.

8. The governing body exercises effective oversight of:

8.1 The strategic management of the institution's land and buildings;

8.2 The institution's employment policies;

8.3 Arrangements for student representation, consideration of student grievances, and student discipline; and

8.4 Procedures to safeguard the health and safety of employees, students and other individuals while they are on the institution's premises, or in other places where they may be affected by its operations.

$\begin{array}{lll} & 4.36 & \text { VS } \\ \text { Criterion 1 Mean } & 4.43 & \text { VS }\end{array}$

Criterion 2 Management

1. Its academic, financial, quality assurance, and resource allocation policies are coherent and appropriate; and relate to its mission, aims and objectives.

2. Its policies and systems are developed and implemented in a manner that involves faculty and, where appropriate, students.

3. Its mission, and associated policies and systems, are understood, accepted and implemented by staff.

4. It is responsive to national policies for and international developments in higher education.

5. It has effective channels of communication with its key stakeholders, its faculty and its students.

6. It has effective systems in place to monitor the implementation of its policies and the performance of its programs

\begin{tabular}{rrr} 
& 4.48 & VS \\
Criterion 2 Mean & 4.31 & VS \\
KRA 1 Mean & 4.37 & VS \\
\hline
\end{tabular}

The regular meetings of the governing body are means of monitoring regularly the performance of the institution against its planned strategies and operational targets. Middle managers are convened to discus issues and concerns directly affecting them so that necessary support can be given.

The six schools have sound financial management, insuring the solvency and safety of its assets (4.49 VS). They have internal and external auditors and a panel of consultants to help them arrive at sound decisions. There are investments of the schools in banks and other financial institutions. The governing body of sectarian schools meets more frequently and is able to function more actively than the governing body of nonsectarian schools. When the President is the Chairman of the Board, decisions are made that may not require Board meeting.

The governing body approves the financial strategy, annual operating plans and budgets of the institution, and ensures the existence and integrity of financial control systems (4.38 VS). This indicator is done during summer before the 
opening of the first semester to make these ready for the next school year. The approval usually is preceded by a performance review of the operations of the current school year. The lessons learned are used in the next school year.

The governing body insures that funds provided by CHED and other funding bodies are used in accordance with the terms and conditions specified when these funds were made available (4.44 VS). The schools observe fiscal autonomy wherein funds allocated for a specific purpose can not be used for other programs. The schools present liquidation papers for funds entrusted to them such as scholarship funds for tuition.

Most schools employ the services of the Sycip Gorres Velayo, Punongbayan and Araullo and other local auditing firms in the area. In some cases, the internal auditor is not a full-time employee but contracted for such purposes. Most schools have consultants who provide for matters needed by the management.

The schools exercise oversight of the strategic management of land and buildings (4.63 E) by optimizing their use and profitability. Also, employment policies are reviewed to see if these are updated and competitive. There is limited arrangement for student representation in the governing body, often invitational only as the need arises (4.25 VS). There are clear provisions for student governance and student discipline, which is supervised by the dean of student affairs. The procedures to safeguard health and safety of employees, students and other individuals are very satisfactory. Notices for proper evacuation are posted in strategic places. There are fire and earthquake drills (4.36 VS).

Criterion 2 focuses on the institution's management, financial control, and quality assurance arrangements. There are sufficient mechanisms to manage existing operations and to respond to development and change.

The schools' academic, financial, and quality assurance and resource allocation policies are coherent and appropriate and relate to their mission and objectives. Half of the schools have ISO certification. However, all of them have accreditation by PAASCU and PACUCOA. One school is accredited by both accrediting agencies. ISO and accreditation are quality assurance programs that aim to promote efficiency and effectiveness of governance and management. The framework for ISO and accreditation proceeds from the vision, mission, and quality policy of the institution.

The schools have involved the stakeholders - the administrators, faculty, staff, and students - in the implementation of policies and systems (4.24 VS). There is a culture of dialogue among the stakeholders. As part of the requirements for accreditation, purposes and objectives are constantly reviewed, disseminated, and evaluated to make sure these are understood, internalized, and lived by the academic community (4.23 VS). 
The quality assurance programs are responsive to national policies and international development in higher education (4.47 VS). The benchmarking of best international practices contributes to this direction. The communication channels are operational and allow for free flow of ideas. The culture of dialogue promotes peace and solidarity within the institution (4.21 VS). The schools have effective systems in place to monitor the implementation of their policies and the performance of their programs (4.48 VS). This is done through formal evaluations, focus group discussions during council meetings, and self surveys for accreditation and compliance of ISO.

For governance and management, the strengths of the schools are the following: approval of strategic plan of the institution, internal and external audit, strategic management of land and buildings, monitoring of the implementation of policies and performance of programs, and responsiveness of the quality assurance programs to national and international developments in higher education.

The growth points include the following: transparency in business transactions, student representation in governance, effective channels of communication, and awareness, internalization and demonstration of vision, mission, policies and systems.

\section{Quality of Teaching and Research}

There are three indicators that measure quality of teaching and research: setting and achieving program standards, centers of excellence and development, and research capability (Table 3 ).

1. Setting and Achieving Program Standards

Table 3. Respondents' ratings on quality of teaching and research (KRA 2)

\begin{tabular}{|c|c|c|}
\hline $\begin{array}{l}\text { Core Indicator A. Setting and Achieving Program Standards } \\
\text { Criterion 1. Program Approval }\end{array}$ & Mean & VD \\
\hline 1. Its degree and other programs meet the standard of the Qualifications & & \\
\hline $\begin{array}{l}\text { Framework, and of any subject specific standards promulgated from time to } \\
\text { time by CHED. }\end{array}$ & 4.45 & vs \\
\hline $\begin{array}{l}\text { 2. It established and maintains comparability of standards with other providers of } \\
\text { equivalent level programs, through seeking advice from academic peers on } \\
\text { other higher education institutions in the Philippines and abroad, and from } \\
\text { relevant professional bodies and employment interest. }\end{array}$ & 4.24 & VS \\
\hline $\begin{array}{l}\text { 3. It has in place effective systems of periodic self-evaluation of individual } \\
\text { programs. }\end{array}$ & 4.35 & VS \\
\hline $\begin{array}{l}\text { 4. It has in place robust procedures for the initial approval and periodic review of } \\
\text { academic programs so as: }\end{array}$ & 4.37 & VS \\
\hline $\begin{array}{l}\text { 4.1 To ensure that they remain in current and valid in the light of } \\
\text { developments in the relevant field of study and related employment } \\
4.2 \text { To evaluate the continuing effectiveness of the curriculum and } \\
\text { assessment in relation to the intended learning outcomes, and to current }\end{array}$ & 4.35 & vS \\
\hline developments in pedagogy. & 3.97 & VS \\
\hline $\begin{array}{l}\text { 4.3 To ensure that the coherence of programs with multiple elements or } \\
\text { alternative pathways is secured and maintained. }\end{array}$ & 3.99 & VS \\
\hline $\begin{array}{l}\text { 4.4 To evaluate the extent to which the intended learning outcomes are } \\
\text { being achieved by students }\end{array}$ & 3.99 & VS \\
\hline $\begin{array}{l}\text { Core Indicator A. Setting and Achieving Program Standards } \\
\text { Criterion 1. Program Approval }\end{array}$ & MEA N & VD \\
\hline
\end{tabular}


(Table 3. Continued)

\begin{tabular}{|c|c|c|}
\hline $\begin{array}{l}\text { Core Indicator A. Setting and Achieving Program Standards } \\
\text { Criterion 1. Program Approval }\end{array}$ & Mean & VD \\
\hline $\begin{array}{l}\text { 5. It takes active steps to ensure that its arrangements for student assessment are } \\
\text { valid, reliable, secure and externally verified. }\end{array}$ & 4.19 & VS \\
\hline 6. There is an effective link between academic planning and resource allocation & 3.96 & VS \\
\hline $\begin{array}{l}\text { 7. Graduate programs are supported by relevant research or other advanced } \\
\text { scholarship. }\end{array}$ & 3.72 & vs \\
\hline Criterion 1 Mean & 4.16 & VS \\
\hline $\begin{array}{l}\text { Criterion } 2 \text { Program Monitoring } \\
\text { 1. The effectiveness of teaching and learning is monitored in relation to }\end{array}$ & & \\
\hline $\begin{array}{l}\text { curriculum content and the learning outcomes of programs } \\
\text { 2. There is effectives matching of the abilities and aptitudes of students to the } \\
\text { demands of the programs to which they are recruited. }\end{array}$ & 4.30 & VS \\
\hline $\begin{array}{l}\text { 3. There is sufficient academic support and counseling available to students to } \\
\text { enable them to progress within their programs of study. }\end{array}$ & 4.11 & VS \\
\hline 4. Students receive timely and effective monitoring on their progress. & 4.02 & VS \\
\hline 5. There are adequate learning resources available to support each program & 4.08 & VS \\
\hline 6. There is a culture of continuous improvement in the delivery of programs. & 4.44 & vS \\
\hline Criterion 2 Mean & 4.31 & VS \\
\hline $\begin{array}{l}\text { Criterion } 3 \text { Action Strengthen Programs } \\
\text { 1. Effective action is taken in response to matters raised through self-evaluation, }\end{array}$ & & \\
\hline $\begin{array}{l}\text { formal internal monitoring, or external review. } \\
\text { 2. Feedback from faculty, students, employers, and higher education institutions }\end{array}$ & 4.45 & VS \\
\hline to which students progress is secured, evaluated and acted upon. & 4.01 & VS \\
\hline $\begin{array}{l}\text { 3. Effective mechanism exists for disseminating good practice throughout the } \\
\text { institution. }\end{array}$ & 4.15 & VS \\
\hline $\begin{array}{l}\text { 4. Weaknesses in student performance identified through assessment are acted } \\
\text { upon }\end{array}$ & 3.80 & VS \\
\hline Criterion 2 Mean & 4.31 & VS \\
\hline KRA2 Mean & 4.19 & VS \\
\hline Indicator B. Center of Excellence and Development & & \\
\hline 1. It benchmarks its performance regularly against best practice internationally. & 3.67 & VS \\
\hline 2. It disseminates best practice from its centers throughout the institution. & 4.02 & VS \\
\hline $\begin{array}{l}\text { 3. It publishes materials that are designed to enable other institutions to learn } \\
\text { from its experience. }\end{array}$ & 3.50 & VS \\
\hline $\begin{array}{l}\text { 4. In the areas of expertise of its centers it is valued as a partner by other higher } \\
\text { education institutions and by related scientific and industrial organizations. }\end{array}$ & 3.65 & VS \\
\hline $\begin{array}{l}\text { 5. It has a faculty development strategy that provides faculty with opportunities } \\
\text { to learn from the work of its centers. }\end{array}$ & 3.85 & VS \\
\hline Indicator B Mean & 3.74 & VS \\
\hline Indicator C. Research Community Capability & & \\
\hline $\begin{array}{l}\text { 1. It has an overall strategy for the management and development of its research } \\
\text { activities, and the provision of research facilities. }\end{array}$ & 4.08 & VS \\
\hline $\begin{array}{l}\text { 2. Its research addresses national needs and priorities, and its outcomes are } \\
\text { utilized. }\end{array}$ & 3.42 & $\mathrm{~S}$ \\
\hline 3. At least some of its researches are at levels of international excellence. & 3.29 & S \\
\hline 4. It is successful in securing income for its research activities. & 3.06 & $\mathrm{~S}$ \\
\hline $\begin{array}{l}\text { 5. A proportion of its faculty has research experience in other universities in the } \\
\text { Philippines and abroad. }\end{array}$ & 3.06 & $\mathrm{~S}$ \\
\hline 6. It provides effective support to its postgraduate research students. & 3.34 & $\mathrm{~S}$ \\
\hline $\begin{array}{l}\text { 7. It contributes to the community through the effective transfer of know-how, } \\
\text { technology and applications of knowledge. }\end{array}$ & 3.68 & VS \\
\hline Indicator $\mathrm{C}$ Mean & 3.42 & VS \\
\hline KRA 2 Mean & 3.84 & VS \\
\hline
\end{tabular}

There are three criteria for this indicator: program approval, program monitoring, and action to strengthen programs.

Before any degree can be offered, the schools have to meet the minimum standards of CHED unless they are granted autonomous status. The data (4.45 VS) reveal that they have complied with the assessment standards of the Regional Quality Assurance Team that visited them to verify the documents submitted. 
The course descriptions are in consonance with technical panel recommendations for general education and major subjects. Such matching ensures that subjects are credited when students transfer to other school.

One benefit also of accreditation is comparability standards wherein the subjects taken in one school are credited by another school. The limitation, however, is that the schools have not established comparability standards with schools abroad.

The practice of most schools is to evaluate individual programs three years after the first batch of graduates and when there is a need for revision of the curriculum. The system of evaluation is operationalized by the academic curriculum committee composed of deans and chairpersons together with the vice president for academic affairs. The procedures for initial approval and periodic review of academic programs are contained in the administrative manual and the curriculum committee is reflected in the organizational chart.

Some schools invite employees and alumni to review the academic programs to meet the expectations of relevance (4.37 VS). Then, as part of accreditation requirements, the curricula are evaluated in relation to intended learning outcomes such as performance results in the board exams and current developments in pedagogy. The objectives of the programs are evaluated regularly. Programs with multiple elements like several majors are examined to avoid duplication of content. Programs with multiple pathways or ladderized like AHSE are given adequate attention. Some schools apply value-added tests to see the impact the curriculum has on intended learning outcomes. Others have comprehensive exams and interviews before students are accepted in the third year and every semester thereafter to see if there is mastery and retention of learning.

Most schools do not maintain test banks. They do not usually conduct item analysis for the examinations made. However, student assessment for aptitude test in nursing, education, accountancy, law, and engineering is done by the Center for Educational Measurement, an external testing agency based in Makati. The results are included as basis for acceptance of students in the major field.

The practice of schools is that deans and chairs make plans as basis for the budget for the next school year, and then the deans defend their budget before a budget committee. Priorities are determined. Hence, there is an effective link between academic planning and resource allocation (3.96 VS). In some schools, researches among graduate students follow the institutional research agenda. There are scholarship grants given by the Civil Service Commission, the LGUs, and private agencies. These arrangements indicate that graduate programs are supported by relevant research or other advanced scholarship (3.72 VS).

The second criterion is program monitoring. The institutions have effective 
arrangements for monitoring the effectiveness of their programs.

The teachers use syllabi that outline class activities. ISO certified schools have IGs or instructors' guides that specify what will be done during class. The chairs and deans monitor the lesson coverage either through weekly checking or through classroom observation. During examination time, the teachers make a table of specifications as basis for the construction of test content. For basic courses, departmental tests are given to see the performance of students under different teachers. The results of the exams are processed by department/college and become the basis for subsequent remedial instructions for the slow learners. Thus, the effectiveness of teaching and learning is monitored in relation to curriculum content and the learning outcomes of programs (4.30 VS).

The entry requirements for different courses vary with respect to high school grades, aptitude, and intelligence. There are cut-offs by program to match students' aptitude with their abilities. Board courses have more stringent requirements (3.87 VS). In most schools, program chairs monitor the progress of the students in major subjects (4.11 VS); for general education, the faculty adviser. Attendance is closely monitored. Those whose absences have reached the tolerable limit are required to present re-entry form from the guidance counselor. The deans inform the parents of the status of the students. Grades are given every grading period. Another practice is the semestral deliberation by the faculty to determine who should be retained. Thus, students receive timely and effective monitoring in their programs (4.02 VS).

In compliance with accreditation standards, schools have accumulated adequate learning resources to support each program (4.08 VS). Some schools provide subsidy to the library and laboratories if the collected fees are not enough. The supervision of CHED and the regular visits of accreditors have assured a culture of continuous improvement in the delivery of programs (4.04 VS).

Action to strengthen programs addresses weaknesses, builds on strengths, and enhances performance by the dissemination of good practice.

The academic chairperson meets regularly with the faculty. The concerns generated are discussed in the monthly meeting with the deans. The Deans' Council meets once a month. Results of classroom observations are discussed with the teacher in a post conference within 72 hours of the visit. Results of semestral evaluation are given to the teachers with corresponding conference to map out plans for the next semester's adjustments. Self- survey teams present their findings to the big group for validation. Weaknesses in the self- survey are communicated to the management for immediate action. The VPAA monitors the progress of the deans against the plans and the Gantt chart of activities. The deans submit semestral and annual reports to the VPAA. The external review is done 
by RQUAT for new programs and by accreditors of programs under accreditation. The recommendations are translated into plans of action that are implemented and documented. Thus, effective action is taken in response to matters raised through self-evaluation, formal internal monitoring, or external review (4.45 VS).

Getting feedback on students' progress is secured in a number of ways (4.01 VS). One is from partner institutions abroad for HRM students. Hotels and restaurants are asked for evaluations of the performance of the trainees. In the local front, the immediate supervisors give evaluation of the on-the-job trainees. These are channeled through the OJT faculty coordinator or through the dean. Tracer studies elicit feedback from employers. These feedback mechanisms serve as basis for improvement of program content and processes.

The dissemination of good practice is done in various ways such as a demo on the latest teaching method by senior faculty. Research dissemination across departments is another good practice. Cross-departmental composition of inhouse accreditation teams allows for sharing of good practice. The in-house publications also carry good practice. Professional sharing by invited experts allows for transfer of knowledge. Thus, the dissemination of good practice is very satisfactory (4.15).

The weakness in student performance is identified through the results of diagnostic tests, periodic examinations, content area analysis of board examinations, and performance in competency tests. The findings are the basis for remedial programs. Thus, the assessment results are properly acted upon (3.80 VS). 2. Centers of Excellence and Centers of Development

The institutions are able to sustain high levels of excellence in teaching, research, and extension services.

In CARAGA Region, St. Paul University System is the Center of Development for Teacher Education. In Region 10, Liceo de Cagayan University is the Center of Excellence in Nursing Education.

For purposes of documenting practices, the six schools were made to answer this section.

The schools claimed they benchmark their performance regularly against international best practices (3.67 VS). Since graduates find employment abroad, the curricula take into account international standards. For instance, Capitol University, St. Joseph Institute of Technology, and St. Paul University System of Surigao City have ISO certifications while Liceo de Cagayan University is deregulated and Lourdes College and Urios College are on their way to higher levels of accreditation. ISO and accreditation standards are benchmarked from international best practices. Recently, the quality assurance program of CHED, which mandates compliance of all schools, has its origin in Europe's practices. 
St. Paul University System, as Center of Development, has done its share as a teacher training institution in the region. Teachers in the region go there for further trainings. Liceo de Cagayan University serves Regions 9, 10, and 13 as Center of Excellence in Nursing Education. Other schools also disseminate good practices by sponsoring trainings tapping in-house experts as well as national and international experts. Every year, Liceo de Cagayan University has activities conducted by the Office of International Affairs for HEIs in the region. Other schools also send their experts to other schools and agencies.

The six schools have publications both instruction and research. However, few schools have internationally serialized research journals and books. Most schools have journals, locally refereed. The schools have publication exchange program with other schools here in the Philippines. However, few schools have international publication exchange program. The schools are valued partners of government and semi government agencies. Such partnerships build the prestige of the schools. Industrial organizations have sought partnerships with these schools both for research and on-the-job trainings. The centers of excellence and development have faculty development program in the form of trainings, thesis/ dissertation grant, and graduate degree programs. They also have funding for publications to disseminate good practice (3.85 VS).

Research capability insures that the school has a research community of faculty, post-graduate students, and post-doctoral research students that fosters and supports creative research and other advanced scholarly activity.

The schools have strategy for the management and development of their research facilities (4.08 VS). There is a research office with budget and material logistics and technology necessary to support research program. Research agenda serve as framework in the design of researches. Few schools charge their students for refereed publication to generate income other than the institutional allocation. The research activities include training of teachers, publication, and public dissemination of research findings. There are research policies to guide their operations.

Most researches address only institutional needs since teachers do schoolbased research. Few studies done outside of the schools address national needs and priorities (3.42 S), and their outcomes are utilized. The satisfactory rating for researches being at par with international excellence (3.29 S) indicates that the research centers have not reached a level by which they have forged international partnerships, or at most, local partnerships. This is affirmed by a lack of funds for research activities (3.06 S) since researches are supported primarily by schoolgenerated funds.

Few of the faculty members have research experience in universities here and 
abroad (3.06 S), limiting their ability to support post graduate research students (3.34 S). Most studies are surveys that do not contribute much to the body of knowledge.

Among the strengths of the schools as regards teaching and research are the following: compliance of degree programs with standards of CHED, effective system for evaluation of individual programs, system of monitoring teaching and learning in relation to curriculum content and learning outcomes, a culture of continuous improvement in the delivery of programs, effective actions to meet findings of self- evaluation, formed internal monitoring and external review, dissemination of best practice, and a strategy for the management and development of research activities, and provision of facilities.

The development concerns are the following: support of relevant research to graduate programs, matching abilities and aptitudes of students to the demands of the programs, assessment as a tool to identify weaknesses of student performance, publication of best practice for other schools to learn from, partnership with scientific and industrial organizations, benchmarking of performance against best international practices, making researches address national needs and priorities, dissemination and utilization of research outcomes, raising research quality to international level, sourcing of funds to support research, expanding research experience of faculty to other universities in the Philippines and abroad, and support to post-graduate research students.

\section{Support for Students}

Support for students has three indicators: student scholarships, equity and access, and student services (Table 4 ).

\section{Student scholarships}

The schools have scholarship coordinators who implement the various grants sponsored by the administration and those sponsored by external agencies. There are clear guidelines for eligibility criteria and procedures for selection of the scholarship awards. Most of the scholarships are intended for access to higher education. Scholarships on merit system have grade requirements like no grade below 1.5. However, there are few scholarships for the indigenous peoples and the handicapped. 
Table 4. Respondents' ratings on support for students (KRA3)

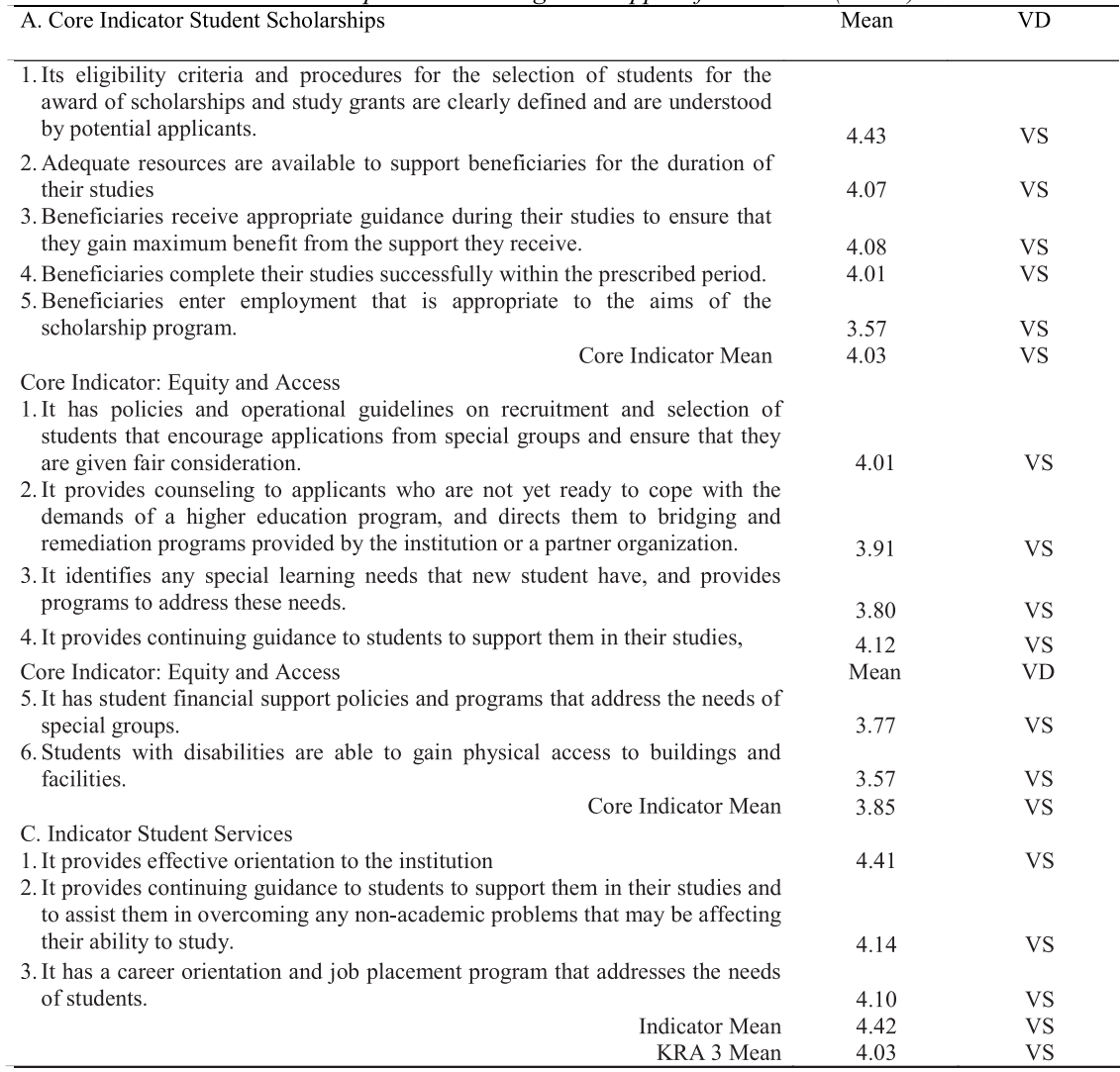

Most of the time, the scholars receive minimal supervision as they are usually self- driven and fully aware of the requirements. Some finished their studies while on grant despite the relative absence of a strong tracking system. They passed licensure exams and brought honors to their school. Some were hired after graduation to teach in their alma mater. Generally, the scholars on merit had higher employability and found job on the first year after graduation.

\section{Equity and Access}

The institution is effective in recruiting, admitting, supporting, and graduating students, who are from indigenous groups, handicapped, from low-low income class, and foreign students. The schools have scholars who are from the low income class and take on the task as working students. They have free tuition and, in some cases, they receive compensation. However, they have to maintain the grade requirements.

Most schools practice open admission. Students take intelligence and aptitude 
Liceo Journal of Higher Education Research

tests and are guided in the choice of course that matches their ability. Those with low entry skills are made to take remedial courses like English $\mathrm{O}$ or English Plus and Math O. Remedial reading is offered in some schools using the SRA. It is evident that the private schools strive to provide access to education with structures and processes that insure the quality of education. Some schools use diagnostic tests like the ones from the Center for Educational Measurement to find specific knowledge or skills that need remedial instruction or enrichment. The guidance center provides the necessary assistance in helping students cope with adjustment problems. The government agencies offer opportunity for access such as the Rebel Returnees Grant, the National Integrated Study Grant, and National Commission for Indigenous Peoples Grant, and the private education students' financial assistance, among others. Despite the programs available, only a very small percentage of the student population is served by these grants.

Generally, the physical structures of the buildings are not yet handicapfriendly. In one university, however, wheel-chaired students can use the flatsurfaced ways in going up or down the buildings.

\section{Student Services}

The institutions have programs for student services to support the nonacademic needs of the students.

The schools have adequate orientation program on student services at the start of classes for new students and transferees. School offices have brochures and bulletin displays for information. The student services complement the academic needs of the students. The guidance center has career orientation and job placement program for graduating students to prepare them for the world of work.

In terms of support to students, the strengths of the schools include the following: clear guidelines on eligibility criteria for selection of students for scholarship grants, guidance to support students in their studies, strong student services orientation program, and continuing guidance for students.

The areas that may need enhancement include the following: scholarship assistance, work placement after graduation, provision of physical facilities for students with disabilities.

\section{Relations with the Community}

This KRA has one core indicator (relevance of programs) and two supplemental indicators (networking and linkages and extension programs).

Relevance of programs means that the institution offers programs that take into account the social, cultural, economic, and development needs of the country at local, regional and national levels as well as the need for the country to compete effectively in global markets. 
Table 5. Respondents' ratings on relations with the community (KRA 4)

A. Core Indicator: Relevance of Programs $\quad$ Mean

1. It offers programs that contribute to the achievement of national priorities in fields such as poverty alleviation, environmental management and health.

2. It has partnerships, arrangements for dialogue, with professional organizations and industry, and that these inform the content and design of programs

4.12

3.98

3.94

3.86

3.98

Indicator Mean changing patters and requirements of employment, and to the needs of the community

4. A significant proportion of its graduates enter employment in which the abilities developed through their higher education are utilized.

Core Indicator: Networking and Linkages

1. It has a range of partner organizations and consortium arrangements appropriate to its mission and programs.

2. It has faculty and student exchange and placement projects with partner organizations.

3. It participates in academic networks at subject and institutional levels.

4. It is able to access expertise through its partnerships

5. It is able to ensure project funding through its partnerships.

Indicator Mean

A.Core Indicator: Faculty Profile

1. It contributes to the local community through programs designed to transfer technology and know-how to individuals and organizations.

2. Extension programs are provided as a part of a sustainable strategy of working with the local community and responding to local needs.

3. It has effective links with local government and community organizations, and these are used to define the priorities for extension programs.

4. It has adequate resources in place to support its extension programs.

5. Lessons from extension programs are used to inform the design of research projects and the content of related mainstream academic programs.

Indicator Mean
KRA Mean

3.74

3.12

3.80

3.82

3.28

3.56

Mean

4.25

4.19

4.35

3.93

3.92

4.12

3.88
VS

VS

VS

VS

VS

$\mathrm{S}$

VS

VS

$\mathrm{S}$

VS

VD

VS

VS

VS

VS

VS

VS

VS

The schools are offering programs that contribute to the achievement of national priorities such as poverty alleviation, environmental management, and health (4.12 VS). Both soft and solid courses are offered by the schools from liberal arts to education, commerce and accountancy, criminology, maritime, nursing, and engineering, computer science, and the like. There is hardly a course on environmental management, but most courses contain environmental topics. The programs are accredited by the PACUCOA and the PAASCU. Three of the six schools have ISO certification.

There are partnerships with professional organizations and industries that enrich content and design of programs. Organizations like PICPA, PAFTE, PAGE, BIOTA, MSEP, and PICE contribute to the enrichment of content in the curricular design. The Council of Deans for each discipline also helps a lot in the relevance of programs.

To some extent, the schools elicit the participation of employees and practitioners on curriculum development, determining the needs and expectations of the community. The schools also have tracer studies that track the employment 
of their graduates. These studies are used by the deans, the Alumni Office, and the Placement Office.

\section{Networking and Linkages}

The schools are partners of other HEIs, government, and non-government institutions, and industries, and organization here and abroad.

Most schools have partner organizations and consortium arrangements appropriate to their mission and programs. These are usually with local government and national government offices such as DOST, DOLE, DTI, CHED, TESDA, and DENR. The arrangements concern scholarships, community extension, facilities, faculty development, financing and others.

Faculty and student exchanges are rarely, if ever, resorted to. What is common is visiting professorship where in only the actual services rendered are contracted. There are academic networks at subject and institutional levels, such as, the College English Teachers Association, PICPA, and Biology Teachers Association for academic network and CEAP, COCOPEA, and PACU for institutional levels. Various concerns on policy, standards, programs, and teaching and learning are raised, discussed, and acted upon. Project fundings are available through partnership (3.28 S). The findings suggest that networking and linkages are in place. However, these have not been optimally utilized to generate funds for projects and faculty-student exchanges.

Networking and linkages are rated very satisfactory.

\section{Extension Program}

This criterion stipulates that the institution is valued by its local community as provider of extension programs that are responsive to the needs of the community for people empowerment and self-reliance.

The schools generally contribute to the local community through programs designed to transfer technology and knowledge to individuals and organizations (3.73 VS). The schools have installed extension programs from the time they applied for accreditation. They have adopted communities and have used COPAR technology. There are needs analyses, community involvement of residents/ beneficiaries, and inputs from the barangay leaders. The academic expertise of the faculty and students are utilized in the community. There is a 5-year period for the withdrawal of community extension programs to allow communities to adopt the program and manage it on their own. The local government units are consulted in the identification of barangays as beneficiaries so as not to duplicate existing intervention programs and to make sure the barangays do need external assistance.

The schools have regular budget to run the yearlong operations. There are provisions such as an office, a coordinator, staff, and material logistics. Teachers are trained for extension work and students are given orientation for community 
extension. Other schools involve only the third to fifth year students who have already studied their major subjects that equipped them to serve better. The extension programs usually include livelihood, housing for the poor (Habitat), health services, leadership training, entrepreneurship, literacy, spiritual enrichment, environmental management, and academic development of students like tutorials for English, Science and Math, and coaching for competitions.

The schools reported that the experiences learned by the teachers and students are integrated into classroom instruction and research. Such learnings find their way into the enrichment of the syllabi, design of instructional materials, and content of research. Regular evaluations are conducted to elicit feedback from beneficiaries and implementors.

Extension program is rated very satisfactory.

Among the strengths of the schools in terms of relations with the community are the following: matched academic programs and national development goals, links with local government and community organizations for extension programs, and contribution to the local community through programs designed to transfer technology and knowledge to individuals and organizations.

The areas that need improvement include the following: employability of graduates by developing abilities the community demands, faculty and student exchange and placement projects with partner organizations, project funding through partnerships, and utilization of lessons learned in the community for research and instruction.

\section{Management of Resources}

The KRA on management of resources has three core indicators: faculty profile, use of information and communication technology, and income generation (Table $6)$.

\section{Faculty Profile}

The six schools generally complied with the minimum requirements of CHED and accreditation on relevant professional qualifications (3.90 VS). Completion of a masters degree is a requirement for tenure. There is a faculty development program that provides for the advanced education of teachers. There are some limitations however. Some teachers have MAs not in line with their specialization because their major fields are not offered in the graduate programs of the schools in the local area. Only a few have been sent for full-time study since the school pays for the salaries of the grantees and their substitutes. Some grantees have not returned while the others have failed to finish the study. Others have not yet completed the study; hence the study has been extended. Rarely do schools hire $\mathrm{PhD}$ holders from outside. 
Generally, the PhDs are homegrown; that is, they studied while on active duty. The financial support is also limited so that only those whose fields of priority studied first. The rest paid on their own. Many were recipients of CHED scholarship grants administered through FAPE.

There are in-service trainings conducted among teachers, but often these are of general nature or interdisciplinary to minimize cost (3.87 VS). Updating is done through peer sharing, echo seminar, and other sessions. The Council of Deans and professional organizations also conduct trainings and updates. There are more opportunities for general education than for the specialized fields.

There is a comprehensive evaluation of instructional performance (4.25 VS) for students, chairpersons, and deans. There is a diminishing importance given to selfevaluation because such is subjective. The evaluation results serve primarily for ranking purposes and, at certain times, as basis for training.

Faculty members join professional organizations and interagency committees (3.69 VS). There is generally a spirit of volunteerism and willingness to accept nonteaching assignments to serve others. The interagency committees are covered by official agreements between the schools and their partners.

Faculty profile obtained a very satisfactory rating.

\section{Use of Information and Communication Technology}

This criterion specifies that institutions must make effective use of information and communication technology to support student learning and to manage their academic affairs.

There has been an effective linkage between academic planning and the allocation of ICT resources (4.10 VS). The practice of schools is to subsidize the cost for ICT resources to augment the laboratory fees paid for by the students. The costs of hardware, software, and licensing have risen over the past years to an extent that the rates are higher than the rates of increase in school and ICT fees. Schools shifted to Linux software in the wake of raids conducted by the NBI. ICT is an important feature in the academic planning because schools want their students to have adequate ICT exposure. Teachers have been trained for computer-aided instruction. The support of ICT to student learning (3.77 VS) is exemplified in a number of ways. One is through the Internet as the window for knowledge acquisition and sharing. Libraries have on-line public access system (OPAC) and have Internet terminals. There are students who prefer surfing the net to borrowing books in the library. Few teachers use laptop in their classes. When using LCD, they need to book its use ahead of time because the use of the LCD is limited. However, they can use the school's laptops whenever a reservation for use is made. 
Table 6. Respondents' rating on management of resources (KRA

\begin{tabular}{|c|c|c|}
\hline A. Core Indicator: Faculty Profile & Mean & VD \\
\hline \multicolumn{3}{|l|}{ 1. A significant proportion of faculty members have relevant $\mathrm{MA}$ or $\mathrm{PhD}$} \\
\hline $\begin{array}{l}\text { degrees, relevant professional qualifications, or relevant industrial experience. } \\
\text { 2. All faculty members are fully up to date with developments in their academic }\end{array}$ & 3.90 & VS \\
\hline field and have mastery of the content and context of the programs they teach. & 3.87 & VS \\
\hline \multicolumn{3}{|l|}{ 3. It has in place a faculty development program that provides training in } \\
\hline pedagogy, and offers formal qualifications in teaching & 4.05 & VS \\
\hline \multicolumn{3}{|l|}{ 4. It has in place arrangements for the systematic evaluation of the performance } \\
\hline $\begin{array}{l}\text { 5. It has in place appropriate incentives for staff to undertake professional } \\
\text { development. }\end{array}$ & 3.82 & VS \\
\hline \multicolumn{3}{|l|}{ 6. Faculty members are active in professional organizations and inter-agency } \\
\hline \multicolumn{3}{|l|}{ 7. Faculty members accept willingly the full range of responsibilities of a higher } \\
\hline Indicator Mean & 3.96 & VS \\
\hline \multicolumn{3}{|l|}{ B. Core Indicator Use of ICT } \\
\hline \multicolumn{3}{|l|}{$\begin{array}{l}\text { 1. There is effective linkage between academic planning and the allocation of } \\
\text { ICT resources }\end{array}$} \\
\hline \multicolumn{3}{|l|}{ 2. It gives active consideration to ways in which ICT might support student } \\
\hline B. Core Indicator Use of ICT & Mean & VD \\
\hline \multicolumn{3}{|l|}{ 3. There is training available for faculty in ways in which they might use ICT to } \\
\hline $\begin{array}{l}\text { 4. There is training available for students in the use of the ICT facilities of the } \\
\text { institution. }\end{array}$ & 4.16 & VS \\
\hline \multicolumn{3}{|l|}{$\begin{array}{l}\text { 5. Where programs are supported by ICT there is adequate student access to } \\
\text { terminals and other equipment. }\end{array}$} \\
\hline Indicator Mean & 3.97 & VS \\
\hline \multicolumn{3}{|l|}{ C. Core Indicator Income Generation } \\
\hline \multicolumn{3}{|l|}{$\begin{array}{l}\text { 1. It has succeeded in generating income from programs and projects, and that } \\
\text { there can be confidence that its forward plans will maintain and increase its }\end{array}$} \\
\hline 2. It is active in appraising potential sources of new income & 3.73 & VS \\
\hline \multicolumn{3}{|l|}{ 3. It takes a prudent attitude to the management of risk in financial matters } \\
\hline \multirow{3}{*}{$\begin{array}{l}\text { 4. It has a network of strong and active links with government and non- } \\
\text { government funding agencies in the Philippines and overseas. } \\
\text { 5. Funds gained for specific projects produce the outcomes specified by the } \\
\text { funder. } \\
\text { 6. It carries out effective monitoring and evaluation of its income generating } \\
\text { activities. }\end{array}$} & 3.55 & VS \\
\hline & 3.50 & VS \\
\hline & 3.80 & VS \\
\hline Indicator Mean & 3.75 & VS \\
\hline KRA Mean & 3.89 & VS \\
\hline
\end{tabular}

The training of students on the use of ICT is formal and done in computer classes. Students have varying needs when they attend computer classes. Others are advanced while others are barely literate. The training is more on computer operations. The use of LCD and other sophisticated gadgets is limited among students.

There are adequate terminals for students' use of ICT. However, the repair of equipment is sometimes inadequate due to limited number of computer technicians. There are enough teachers but not enough technicians in some schools. The logistics vary. Laboratory fees range from P1, 200 to about P4, 000 per subject. Schools that collect more are better able to replace non-usable equipment and hire adequate 
personnel.

The schools covered in the study generally have high ICT capabilities due to rising competitions among them. Schools in CARAGA Region, however, generally collect lower lab fees in consideration of the paying capacity of the students. However, their facilities pass the requirements of the accrediting bodies.

The use of ICT is generally very satisfactory.

\section{Income Generation}

The criterion states that the institutions must have viable, sustainable, and appropriate income-generating strategy to support development plans.

Generally, the schools are largely tuition-dependent to support their operations. Most of them adopt a no- tuition fee increase upon first time enrollment until graduation. There are increases in miscellaneous items but these are inadequate to meet the rising cost of operations. The revenues from tuition can support shortterm liabilities. Over the years, the schools have accumulated assets good for future expansion. Some schools have businesses having separate juridical personalities. School-related businesses usually include canteens, bookstore, uniforms, and school supplies.

New increases come from new miscellaneous fees, but these are rarely resorted to keep the gross fees manageable and competitive. Most schools have minimal investments in financial institutions. Most investments have low risk and low yield like time deposits. Some schools have investment managers and consultants that optimize the yield of the school's profits. The profit margin generally is conservative for about 10 percent. Some schools have higher profit margins that are plowed back to the school in the form of investments in real property and academic programs.

The schools use strong and active banks to meet their needs. Most prefer private banks to government banks. All schools have utilized the services of several banks to spread their investments. There has been limited inflow of funds from funding agencies. These funds are for research, facilities, and infrastructure. The schools have been responsible in dispensing financial accountability of funds received or entrusted to them. There are also means to monitor and evaluate income-generating activities such as periodic reports, meetings, and dialogues with partners and school providers.

On the whole, the three indicators are rated very satisfactory. The highest rating went to ICT and followed by faculty profile. Income generation was rated the least. The trend is that institutions generally serve the needs of their clients. The emphasis is more on social responsibility rather than on profit. This trend has also limited the entrepreneurial activities of schools. However, as organizations, they also need 
reasonable return of investment.

The strengths of schools are that they are able to implement a systematic evaluation of performance of teachers, they are willing to accept full range of responsibilities, have trainings for students on ICT use, and they are prudent in the management of financial matters.

For development purposes, they need to address issues of limited involvement of teachers in professional organizations and interagency committees and appropriate incentives for teachers for their achievements. They need to explore ways to motivate teachers to use ICT in teaching and to provide the means by which teachers can use ICT such as LCD, laptop, and Internet. There are limited sources of funds from the outside though the faculty has the expertise. The search for new revenues to augment tuition poses a challenge to the administrators.

The analysis of test of difference in the practice of culture of excellence among the schools is presented in Table 7.

Table 7. Test of difference in the practice of a culture of excellence of the private higher education institutions

\begin{tabular}{lllcl}
\hline & $\mathrm{F}$ & Sig. & Interpretation & Decision on $\mathrm{H}_{0}$ \\
\hline Governance \& Management & 2.126 & .146 & $\mathrm{NS}$ & Accept \\
Quality of Teaching \& Research & 3.667 & .044 & $\mathrm{~S}$ & Reject \\
Support to Students & 5.028 & .017 & $\mathrm{~S}$ & Reject \\
Relations with the Community & 3.090 & .68 & $\mathrm{NS}$ & Accept \\
Management of Resources & 2.066 & .153 & $\mathrm{~S}$ & Reject \\
\hline
\end{tabular}

Among the five KRAs, the schools differed significantly in quality of teaching and research, support to students, and management of resources. The schools have different quality assurance systems: three with both accreditation and ISO and three with accreditation only. Also, three are sectarian while three are nonsectarian. These elements may have caused the variances in the culture of teaching and research, support to students, and management of resources. This means that the practices may be different in form but may be similar in substance as these are designed to produce intended learning outcomes. On the basis of the findings, the null hypothesis is rejected.

\section{Emerging Trends in Practices of a Culture of Excellence in the Private Schools}

1. Schools have been internationalizing their quality assurance programs since they achieved higher levels of accreditation. Two schools had ISO to fulfill a mandate for maritime education. One school did not have maritime program yet it secured the ISO Certification. One reason cited the quality of education is recognized abroad when the ISO seal is marked on the transcript of records, thus, the curriculum is accepted and the graduates are preferred for employment. ISO brings in new "software" of management which perspective to school management is global. 
2. The strongest KRA is on governance and management. It is an inspiring revelation that quality assurance has enhanced the ability of the governing body to implement a quality system that can produce intended outcomes. As long as there is a quality assurance system, a school can be efficient and effective in the delivery of its services.

3. Support for students was the second best KRA, an indication that schools make a difference in the lives of the students by providing them with equal opportunitiesregardless of their state of being.

4. Management of resources was the third best KRA though schools are almost wholly tuition-dependent. Most schools offer zero tuition fee increases. Their astute sense of financial management enables them to develop their faculty and ICT capabilities, and to come up income-generating activities to augment their tuition revenues.

5. Relations with the community were the fourth best KRA. The schools demonstrate relevance of their programs to the communities they serve bolstered by strong extension programs. However, the schools have limited networking and linkages although the opportunities abound.

6. The schools' main expertise is teaching. The faculty has limited research productivity despite provision for research opportunities. Since research is a defining character of a university as differentiated from teaching for a college, universities must implement a strong research culture if it has to actualize its raison $\mathrm{d}$ etre. Since the structure and resources for research are in place, schools must find effective ways to inspire and capacitate teachers to create knowledge that they can ably teach to their students.

Table 8. Summary of culture of excellence by KRA, indicator and criteria

\begin{tabular}{|c|c|c|}
\hline Indicators & Mean & VD \\
\hline \multicolumn{3}{|l|}{ I. Performance Measures - Governance and Management } \\
\hline \multirow{2}{*}{\multicolumn{3}{|c|}{$\begin{array}{l}\text { Criterion 1: The institution's governance arrangements demonstrate } \\
\text { probity strategic vision accountability }\end{array}$}} \\
\hline & & Ne \\
\hline \multirow{2}{*}{\multicolumn{3}{|c|}{$\begin{array}{l}\text { Criterion 2: The institution's management, financial control, and quality } \\
\text { assurance arrangements are sufficient to manage existing }\end{array}$}} \\
\hline & & \\
\hline respond to development and change & 4.31 & VS \\
\hline KRA Mean & 4.37 & VS \\
\hline \multicolumn{3}{|l|}{ II. Performance Measures - Quality of Teaching and Research } \\
\hline \multicolumn{3}{|l|}{ A. Core Indicator: setting and achieving program standards } \\
\hline \\
\hline $\begin{array}{l}\text { learning outcomes of its programs at appropriate levels, and has effective } \\
\text { mechanisms to ensure that is programs achieve those objectives and enable }\end{array}$ & & \\
\hline students to achieve the intended outcomes. & 4.16 & VS \\
\hline Criterion 2: Program Monitoring. The institution has effective & & \\
\hline arrangements for monitoring the effectiveness of its programs. & 4.14 & VS \\
\hline Criterion 3: Action to Strengthen Programs. The institution takes & & \\
\hline $\begin{array}{l}\text { effective action to address weakness, build on strengths, and to enhance } \\
\text { performance by the dissemination of good practice. }\end{array}$ & 4.10 & Vs \\
\hline 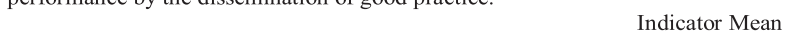 & 4.19 & VS \\
\hline $\begin{array}{l}\text { B. Indicator: Centers Of excellence and Centers of Development } \\
\text { Criterion: In its centers of excellence or of development the institution } \\
\text { sustains consistently high levels of excellence in teaching, research or extension } \\
\text { services. }\end{array}$ & 3.74 & VS \\
\hline
\end{tabular}


(Table 8. Continued)

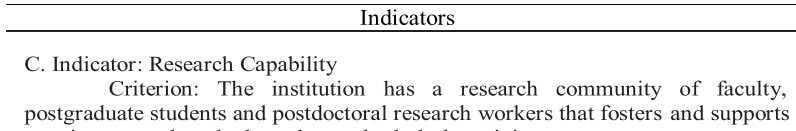
creative research and other advanced scholarly activity.

KRA 2 Mean

III. Performance Measures - Support for Students

A. Core Indicator: Student Scholarships

Criterion: The institution operates effective arrangements to direct scholarships and study grants on merit to support the most able students on programs that develop competences needed to support the Filipino economy and to enable the country to compete in global labour markets.

B. Core Indicator: Equity and access

Criterion: The institution is effective in recruiting, admitting, supporting, and graduating students, including those from indigenous groups, the handicapped, low level income classes, foreign students, and other special groups.

Mean VD

C. Indicator: Student Services

Criterion: The institution has programs for student services, to support the non-academic needs of the students.

KRA 3 Mean

IV. Performance Measures - Relations with the Community

A. Core Indicator: Relevance of Programs

Criterion: The institution offers programs that take into consideration the social, cultural, economic, and developmental needs of the country at local, regional, and national levels, as well as the need for the country to compete effectively in global markets.

B. Indicator: Networking and Linkages

Criterion: The institution is valued as a partner by other higher education institutions; professional, government, non-government organizations; and industry, within the Philippines and internationally.

C._Indicator: Extension Program

Criterion: The institution is valued by its local community as provider of extension programs that are responsive to the needs of the community for people empowerment and self-reliance.

KRA 4 Mean

V. Performance Measures - Management of Resources

A. Core Indicator: Faculty Profile

Criterion: The institution has an adequate number of faculty members with the appropriate expertise and competence to teach the courses offered by the institution.

B. Core Indicator: Use of Information and Communications Technology

Criterion: The institution makes effective use of information and communications technology to support student learning and to manage its academic affairs.

C. Core Indicator: Income Generation

Criterion: The institution has a viable, sustainable and appropriate income-generating strategy to support its development plans.

KRA 5 Mean

Table 9. Summary of culture of excellence by KRA

\begin{tabular}{|c|c|c|c|c|}
\hline KRA & & Mean & VD & Rank \\
\hline 1. Governance and Management & & 4.37 & VS & 1 \\
\hline 2. Quality of Teaching \& Research & & 3.84 & VS & 5 \\
\hline 3. Support for Students & & 4.03 & VS & 2 \\
\hline 4. Relations with the Community & & 3.88 & VS & 4 \\
\hline \multirow[t]{2}{*}{ 5. Management of Resources } & & 3.89 & VS & 3 \\
\hline & Grand Mean & 4.00 & VS & \\
\hline
\end{tabular}




\section{CONCLUSIONS}

The culture of excellence is largely a function of efficient and effective quality assurance management systems such as voluntary accreditation and international certification. The external evaluation in the quality assurance audits promotes the achievement of comparable standards with the best practices in the Philippines and abroad. Some accredited schools have acquired ISO certification, a move that enhances the quality assurance management system.

The schools' culture of excellence generates the intended teaching and learning outcomes manifested through integral development of graduates, high performance in licensure examinations, high employability, and global competitiveness. Thus, the implementation of quality assurance management system enables schools to achieve their vision-mission -goals in higher education.

The efficiency and effectiveness of the governance and management of the schools have an overriding influence on the quality of teaching and research, support to students, relations with the community, and management of resources. Despite limited resources, schools are able to optimize their resources for the promotion of quality and excellence in education.

Generating higher research productivity among the faculty, fund sourcing from partnership and entrepreneurial activities that generate non-tuition revenues remain the serious challenges of the school management. Forging networks and linkages strengthens their resource capabilities.

\section{LITERATURE CITED}

Alcala, A. C. (2000). Graduate education in the Philippines: strategies for reforming higher education towards global excellence. The Cebu Doctors College Graduate Journal Vol. 4 SY 1999-2000.

CHED MEMORANDUM Order No. 15 Series of 2005. Implementing rules and regulations of CMO No. 15 series of 2005.

CHED Memorandum Order No. 16 Series of 2005. Implementing rules and regulations of CMO No.15 series of 2005.

IQUAME Operations handbook for the review team. (2005). The Commission on Higher Education.

Layton, S. (1995). Competitive strategy: planning your organization's success. CA: Crisp Publications, Inc.

Primer on IQUAME (2005). Commission on Higher Education.

Thompson, A. A. \& Strickland, A.J. III(2001). Strategic management: concept and cases: USA: McGraw Hill Higher Education 12 Ed.

Valisno, M. D. (2000). Moving towards comparability: strengthening human resources development in the Philippines. The Cebu Doctors College Graduate Journal Vol. 4 SY 1999-2000. 